\title{
The Relationship Between the Daily and Policy-Relevant Liquidity Effects
}

Daniel L. Thornton

\begin{abstract}
The phrase "liquidity effect" was introduced by Milton Friedman (1969) to describe the first of three effects on interest rates caused by an exogenous change in the money supply. The lack of empirical support for the liquidity effect using monthly and quarterly monetary and reserve aggregates data led Hamilton (1997) to suggest that more convincing evidence of the liquidity effect could be obtained with daily data-the daily liquidity effect. This paper investigates the implications of the daily liquidity effect for Friedman's liquidity effect using a more comprehensive model of the Federal Reserve's daily operating procedure than has been previously used in the literature. The evidence indicates that it is no easier to find convincing evidence of a Friedman liquidity effect using daily data than it has been with lower-frequency monthly and quarterly data. (JEL E40, E52)
\end{abstract}

Federal Reserve Bank of St. Louis Review, January/February 2010, 92(1), 73-87.

T he phrase "liquidity effect" (LE) was first used by Milton Friedman (1969) to describe the first of three effects on interest rates caused by an exogenous change in the supply of money. ${ }^{1}$ Despite its prominent role in conventional theories of the monetary policy transmission mechanism, there has been little evidence of a statistically significant or economically meaningful LE. ${ }^{2}$ Suggesting that previous attempts to identify the LE have been unsuccessful because low-frequency data mix the effects of policy on economic variables with the effects of economic variables on policy, Hamilton (1997) sought to develop a "more con-

1 The other two effects are the "income" and "price expectation" or "inflation expectation" effects (e.g., Friedman, 1969; and Gibson, 1970a,b). These effects have roots in classical economics (e.g., Humphrey, 1983a,b). Because of the inflation expectation effect, an exogenous change in money growth eventually leads to higher, rather than lower, equilibrium nominal interest rates.

2 The empirical literature on the LE dates back at least to Cagan and Gandolfi (1969) and Gibson (1970a,b). vincing measure of the liquidity effect" by estimating the response of the federal funds rate to exogenous reserve supply shocks using daily data. This is referred to as the "daily liquidity effect" (DLE). Thornton (2001a) showed that (i) Hamilton's estimates of the DLE were the consequence of a few extreme observations and (ii) there was no evidence of a DLE using Hamilton's model and methodology for his sample period and for sample periods before or after that period. Recently, however, Carpenter and Demiralp (2006) report evidence of a DLE using a more complete model of the operating procedure of the Trading Desk of the Federal Reserve Bank of New York (hereafter, the Desk) than that used by Hamilton. They also use a reserve supply shock measure that more adequately reflects reserve supply shocks that the Desk creates each day in the conduct of open market operations.

Carpenter and Demiralp (2006) and Hamilton (1997) claim that estimates of the DLE provide

Daniel L. Thornton is a vice president and economic adviser at the Federal Reserve Bank of St. Louis. The author thanks Jim Hamilton and Sherry Edwards for useful comments and Jonathan Ahlbrecht, John McAdams, Daniel McDonald, and Aaron Albert for helpful research assistance.

(C) 2010, The Federal Reserve Bank of St. Louis. The views expressed in this article are those of the author(s) and do not necessarily reflect the views of the Federal Reserve System, the Board of Governors, or the regional Federal Reserve Banks. Articles may be reprinted, reproduced, published, distributed, displayed, and transmitted in their entirety if copyright notice, author name(s), and full citation are included. Abstracts, synopses, and other derivative works may be made only with prior written permission of the Federal Reserve Bank of St. Louis. 


\section{Thornton}

evidence of the existence of the Friedman LE. I argue that evidence of a DLE need not provide evidence of the existence of Friedman's LE. Specifically, I analyze the relationship between the DLE and Friedman's policy-relevant LE. The analysis shows that because of specific features in the Fed's operating procedure, its system of reserve requirements, and other factors, the relationship between the DLE and Friedman's LE is neither simple nor direct. In particular, statistically significant estimates of the former do not necessarily imply the existence of the latter. In so doing, I estimate the DLE using (i) Carpenter and Demiralp's (2006) reserve shock measure and (ii) a more complete model of the Fed's daily operating procedure than that used by either Hamilton (1997) or Carpenter and Demiralp. The empirical evidence indicates that it is no easier to find convincing evidence of Friedman's LE using high-frequency daily data than it has been using monetary and reserve aggregates at monthly or quarterly frequencies.

The remainder of the paper is divided into three sections. The upcoming section investigates the relationship between the DLE and Friedman's LE using a detailed model of the Desk's operating procedure. Following the literature, in the next section I develop estimates of an exponential autoregressive conditional heteroskedasticity (EGARCH) model of the DLE based on the model. The empirical model uses Carpenter and Demiralp’s (2006) reserve supply shock measure.

\section{THE POLICY-RELEVANT AND DAILY LIQUIDITY EFFECTS}

Milton Friedman (1969) termed the first of three effects of an exogenous change in the supply of money on nominal interest rates the "liquidity effect.” Friedman's LE is relevant for monetary policy. Consequently, Friedman's LE is called the "policy-relevant liquidity effect" (hereafter, LE). To understand why the DLE need not imply the existence of the LE, it is important to understand the mechanism that links the DLE to the LE. In this regard, it is important to note that the LE stems from the demand for money; that is,

$$
M_{t}^{d}=f\left(i_{t}, y_{t}\right),
$$

where $M_{t}^{d}$ denotes the demand for money, which, for purposes of illustrating the relationship between the DLE and LE, is assumed to be a simple function of a nominal interest rate, $i$, and nominal income, $y_{t}$. Because individuals tend to economize their holding of money when interest rates rise, $\partial f / \partial i<0$.

Equilibrium requires that the supply of money, $M_{t}^{s}$ (which, for simplicity, is assumed to be exogenously controlled by the Fed), equals demand; that is,

$$
M_{t}^{s}=M_{t}^{d} .
$$

The LE is the initial effect of an exogenous change in the money supply on the interest rates and is given by

$$
d i_{t} / d M^{s}=(\partial f / \partial i)^{-1},
$$

where it is assumed that neither nominal income nor inflation expectations respond immediately to the Fed's actions. Friedman (1969) called equation (3) the "liquidity effect."

Considerable empirical evidence indicates that the demand for money is negatively related to the interest rate and interest inelastic. The interest inelasticity of money demand implies that a small exogenous change in the supply of money should cause a relatively large response in interest rates-a relatively large LE. Consequently, the inability of researchers to find a statistically significant and economically meaningful LE is referred to as the "liquidity puzzle." 3

The failure to find the LE using low-frequency monetary and reserve aggregates has been attributed to several factors, such as the response of nominal income or inflation expectations to money supply shocks and the inability to isolate exogenous monetary shocks. Researchers have attempted to overcome these problems using, among other things, structural vector autoregressions (SVARs). The recursive SVAR, or RSVAR, has been particularly popular in this literature. SVAR models have been estimated using a vari-

\footnotetext{
3 See Strongin (1995).
} 
ety of monetary and reserve aggregates. Pagan and Robertson (1995) show that it is difficult to find convincing evidence of the LE with these models. ${ }^{4}$

The inability of researchers to find evidence of the LE using monthly or quarterly data led Hamilton (1997) to suggest that the failure of the RSVAR approach likely stemmed from the fact that changes in Fed policy are frequently due to information about "current or future values of output, inflation, exchanges rates, or other magnitudes," so that "the correlation between such a 'policy innovation' and the future level of output of necessity mixes together the effect of policy on output with the effect of output forecasts on policy." 5 He suggested that the LE could be more easily identified by estimating the response of the funds rate to reserve supply shocks measured at the daily frequency. Specifically, he estimated reserve supply shocks from a simple time-series model of the Treasury's daily deposits at the Fed. Assuming that the errors from this model proxy the reserve supply shocks that the Desk makes in conducting daily open market operations, Hamilton (1997) estimated the response of the federal funds rate to his estimated reserve supply shocks; that is, he estimated the DLE. He suggested that his estimates of a DLE implied the existence of the LE.

\section{The Relationship Between the Policy- Relevant and Daily Liquidity Effects}

The relationship between the DLE and the $\mathrm{LE}$ is a result of the Fed's imposition of reserve requirements on some components of money. This creates a direct link between the demand for money—the source of LE—and the demand

\footnotetext{
4 The exception is using a RSVAR with nonborrowed reserves as the monetary aggregate. Coleman, Gilles, and Labadie (1996) pointed out, however, that evidence of an LE using nonborrowed reserves may be a consequence of the Desk's efforts to offset the effect of changes in discount window borrowing. Thornton (2001b) confirmed this by showing that the estimated LE using nonborrowed reserves is a consequence of the interest sensitivity of discount window borrowing and the Desk's operating procedure under either monetary aggregate or funds rate targeting. He shows that this "liquidity effect" using nonborrowed reserves vanishes in the early 1980s when borrowing declined dramatically and became relatively interest-insensitive.

${ }^{5}$ Hamilton (1997), p. 80.
}

for reserves-the source of the DLE. This relationship can be illustrated by assuming that the demand for reserves is given by

$$
\text { (4) } R_{t}^{d}=R R\left(M_{t}^{d}\right) \text {, }
$$

where $R_{t}^{d}$ denotes the demand for reserves and $R R\left(M_{t}^{d}\right)$ denotes the Federal Reserve-imposed system of reserve requirements, which depend on the demand for money. Equation (4) shows that the demand for reserves is derived from the demand for money. Hence, in principle, it is possible to estimate the LE by estimating the response of interest rates to an exogenous change in the supply of reserves; that is, by estimating the DLE. The advantage of using daily data is that measures of reserve supply shocks at this frequency cannot be contaminated by the endogenous behavior of the Fed as Hamilton (1997) noted. Moreover, since the response will be identical whether the shock to reserves is due to an error the Desk makes in conducting daily open market operations or is a monetary policy-induced exogenous shock to reserves, there is no identification problem as there is when higher-frequency monetary and reserve aggregates are used. It is sufficient to identify a reserve supply shock from any source.

The strength of this relationship, however, depends both on the Desk's daily operating procedure, which has remained essentially the same since at least the early 1970s, and the Fed's system of reserve requirements, which has not.

The Desk's Operating Procedure. The analysis begins with a model of the Desk's operating procedure. Each day the Desk estimates the quantity of reserves that banks will demand over a maintenance period ending every other Wednesday, called "settlement Wednesday." 6 The Desk also estimates the quantity of reserves that will be supplied if the Desk conducts no open market

\footnotetext{
6 Until October 1979 the estimate of demand was conditional on the objective or target for the federal funds rate. From October 1979 to September 1982, the estimate was conditional on the objective for the growth rate of the M1 monetary aggregate. Beginning in September 1982, the Fed claimed that the estimate was conditional on an objective for borrowed reserves; however, Thornton (2006) provides evidence from Federal Open Market Committee (FOMC) transcripts suggesting that the real objective was the federal funds rate. Today the objective is unquestionably the federal funds rate.
} 
operations that day. ${ }^{7}$ If the former estimate exceeds the latter, the operating procedure suggests that the Desk add reserves through an open market purchase. If the former is smaller than the latter, the procedure suggests that reserves be drained through an open market sale.

Specifically, the Desk estimates the demand for total reserves:

$$
E_{t-1} T R_{t}^{d}=E_{t-1} R R\left(f\left(i_{t}, y_{t}\right)\right)+E_{t-1} E R_{t}^{d},
$$

where $T R_{t}^{d}$ denotes the demand for total reserves, $E R_{t}^{d}$ denotes depository institutions' demand for excess reserves, and $E_{t-1}$ denotes the expectation operator conditional on information available before that day's open market operation.

The supply of reserves available each day is given by

$$
T R_{t}^{s}=B_{t}+B R_{t}+F_{t}+O M O_{t},
$$

where $B_{t}$ denotes the Fed's holding of government debt before that day's open market operation, $B R_{t}$ denotes bank borrowing at the discount window, $F_{t}$ denotes autonomous factors that affect reserve supply-currency in circulation, the Treasury's balance at the Fed, the float, and so on-and $O M O_{t}$ denotes the amount of open market purchases or sales conducted by the Desk that day. ${ }^{8}$

Each day the Desk estimates the supply of reserves that will be available if the Desk conducts no open market operations: $O M O_{t}=0$. The Desk essentially knows the magnitude of $B_{t}$, but it must estimate $F_{t}$. The Desk does not estimate borrowing, but rather applies the Federal Open Market Committee (FOMC)-determined borrowing assumption, called the initial borrowing assumption $\left(I B A_{t}\right) \cdot{ }^{9}$ The estimate of reserve supply if the Desk conducts no open market operations is

\footnotetext{
7 A more detailed analysis of the Desk's operating procedure can be found in Feinman (1993) and Thornton (2001b, 2007).

8 Borrowing (and later the initial borrowing assumption) refers to seasonal plus adjustment borrowing. Extended credit borrowing is treated separately as one of the autonomous factors affecting reserve supply.

9 The initial borrowing assumption was changed relatively infrequently and, most often, when the funds rate target was changed. Thornton (2006) shows that the initial borrowing assumption was last mentioned in discussing monetary policy during a conference call on January 9, 1991. However, it remained part of the Desk's formal operating procedure until at least 1996.
}

$$
E_{t-1} T R_{t}^{s}=B_{t}+E_{t-1} F_{t}+I B A_{t},
$$

where $E_{t-1} F_{t}$ denotes the Desk's estimate of autonomous factors. The amount of the open market operations suggested by the Desk's operating procedure, which I call the operating proceduredetermined open market operation $\left(O D O M O_{t}\right)$, is given by

$$
\begin{aligned}
& O P D O M O_{t}=\left(E_{t-1} R R\left(f\left(i_{t}, y_{t}\right)\right)+E_{t-1} E R_{t}^{d}\right) \\
& -\left(B_{t}+E_{t-1} F_{t}+I B A_{t}\right) .
\end{aligned}
$$

If $O P D O M O_{t}$ is positive, the procedure directs the Desk to purchase securities; if it is negative, the procedure indicates that securities should be sold.

If the Desk follows its operating procedure exactly, $O M O_{t}=O P D O M O_{t}$. The operating procedure is intended only to provide the Desk guidance, however. Judgment is used to conduct each day's open market operation. Indeed, over most of the period examined here, the Desk almost never followed the operating procedure exactly (e.g., Thornton, 2007). To allow for this fact, let

$$
O M O_{t}=O P D O M O_{t}+k_{t},
$$

where $k_{t}$ denotes the amount by which actual open market operation differs from that recommended by the operating procedure.

Reserve market equilibrium requires that the demand for reserves equals the supply; that is,

$$
R R\left(f\left(i_{t}, y_{t}\right)\right)+E R_{t}^{d}=B_{t}+F_{t}+B R_{t}+O M O_{t} .
$$

Substituting equations (8) and (9) into equation (10) yields

$$
\begin{aligned}
& R R\left(f\left(i_{t}, y_{t}\right)\right)=E_{t-1} R R\left(f\left(i_{t}, y_{t}\right)\right)-\left(E R_{t}^{d}-E_{t-1} E R_{t}^{d}\right) \\
& -\left(F_{t}-E_{t-1} F_{t}\right)-\left(B R_{t}-I B A_{t}\right)+k_{t} .
\end{aligned}
$$

The interest rate that equates the reserve market is the federal funds rate, $f f_{t}$. Thornton (2006) shows that the FOMC has been targeting the funds rate to some extent since $1982 .{ }^{10}$ Consequently, the

\footnotetext{
${ }^{10}$ See Thornton $(1988,2006)$ for the relevant evidence.
} 
Desk's expectation of reserve demand is conditional on the FOMC's target for the funds rate. ${ }^{11}$ Consequently, equation (11) can be rewritten as

$$
\begin{aligned}
& R R\left(f\left(i_{t}, y_{t}\right)\right)=R R\left(E_{t-1} f\left(f f_{t}^{*}, y_{t}\right)\right)-\left(E R_{t}^{d}-E_{t-1} E R_{t}^{d}\right) \\
& -\left(F_{t}-E_{t-1} F_{t}\right)-\left(B R_{t}-I B A_{t}\right)+k_{t} .
\end{aligned}
$$

If the reserve supply shock is given by $\left(F_{t}-E_{t-1} F_{t}\right)$, the DLE is given by

$$
\frac{\partial f f_{t}}{\partial\left(F_{t}-E_{t-1} F_{t}\right)}=\frac{1}{R R^{\prime}\left(\partial f / \partial f f_{t}\right)}<0
$$

where $R R^{\prime}>0$. Equation (13) shows that the relationship between the DLE and the LE depends on the Fed's system of reserve requirements, $R R(\cdot)$.

\section{The Role of Reserve Requirements}

Several aspects of the Fed's system of reserve requirements affect the relationship between the DLE and the LE. Important among these is the fact that reserve requirements are not imposed on all components of money. For example, there are no reserve requirements on the currency, and the percentage reserve requirements are different for various components of money.

Also, reserve requirements have changed over time, both exogenously and endogenously. The Fed made two major exogenous reductions in reserve requirements during the past two decades-in December 1990 and April 1992. ${ }^{12}$ In addition, an important endogenous reduction in effective reserve requirements began in 1994 when banks started "sweeping" their retail transactions deposit accounts to reduce their effective percentage reserve requirement (e.g., Anderson

\footnotetext{
${ }^{11}$ For a more detailed explanation, see Thornton (2001b).

12 Effective December 13, 1990, the 3 percent reserve requirement on non-transaction liabilities was reduced to 1.5 percent for weekly reporters; effective December 27, 1990, the 1.5 percent reserve requirement on non-transaction liabilities was reduced to zero for weekly reporters. The combined effect of these actions reduced required reserves by an estimated $\$ 13.2$ billion. Although not reported here, these changes appear to have had no important effect on the estimates of the DLE reported in the next text section. There have been numerous other changes in the Fed's percentage reserve requirements over the years; however, these were relatively small and of little consequence.
}

and Rasche, 2001). The result was a significant reduction in effective reserve requirements and a significant rise in the number of "nonbound" banks-banks that satisfy their reserve requirements with vault cash. ${ }^{13}$ This change has important consequences for the relationship between the DLE and the LE in that it severs the contemporaneous link between money demand and reserve demand for nonbound banks.

Importantly, the Fed reintroduced lagged reserve accounting in July 1998. Beginning with the maintenance period that began on July 30 , 1998, there is a full two-maintenance-period (four-week) lag in the reserve accounting system. Reserve requirements for the current maintenance period now are determined by deposit balances held during the 14-day period two maintenance periods before the current one. This system of lagged reserve accounting severs the contemporaneous link between money demand and reserve demand for all banks, not simply nonbound banks. Hence, there is no contemporaneous relationship between the DLE and the LE after July 1998. Consequently, statistically significant estimates of the DLE after this date (e.g., Carpenter and Demiralp, 2006; and Judson and Klee, 2009) provide no evidence of the LE. The statistically significant negative relationship between the funds rate and reserve supply shocks merely reflects the fact that banks have an incentive to economize on their holdings of non-interest-bearing reserves. This incentive exists even if the demand for money does not depend on the interest rate, because reserve demand is interest sensitive for reasons other than the interest sensitivity of the demand for money.

Finally, Thornton (2001a) has noted a two-day lag in the Fed's prior reserve accounting system from March 1984 to July 1998. ${ }^{14}$ Specifically, a bank's maintenance-period reserve requirement was based on deposit balances held two days before the end of the maintenance period. The lack of a contemporaneous relationship between

\footnotetext{
${ }^{13}$ See Anderson and Rasche (2001) for more details on the effects of retail sweep programs.

${ }^{14}$ From 1968 to March 1984 there was a one-maintenance-period lag in the Fed's system of reserve accounting.
} 


\section{Thornton}

money demand and reserve demand on those days means that evidence of a DLE on the last two days of the maintenance period need not imply anything about the existence of the LE.

Analyses by Clouse and Dow (2002) and Bartolini, Bertola, and Prati (2002), however, show that reserve demand may be related to money demand on the last two days of the maintenance period if individual banks behave optimally with respect to the reserve carryover provision. ${ }^{15}$ These models do not include the costs of operating such procedures, however, and these costs could be large relative to the cost of satisfying a reserve shortfall at the end of the maintenance period through the discount window or in the federal funds market. ${ }^{16}$ Consequently, it is not clear whether such intense reserve managementthough technically feasible-is economically viable. ${ }^{17}$ In any event, even if banks behave optimally, the relationship between the DLE and the LE would be affected by the fact that reserve demand on these days is due to the carryover provision. Consequently, the extent to which estimates of the response of the funds rate to a reserve supply shock on the last two days of the maintenance period provide evidence of the LE is uncertain.

\section{ESTIMATING THE DAILY LIQUIDITY EFFECT}

Hamilton (1997) and Carpenter and Demiralp (2006) estimate the DLE using a model based on a simpler version of equation (12). Estimating the DLE requires several additional assumptions. First, it requires an assumption about the Fed's system of reserve requirements. Effectively, Hamilton (1997) and Carpenter and Demiralp (2006) assume that the Fed's system of reserve

\footnotetext{
${ }^{15}$ I thank Jim Hamilton for pointing out this possibility to me.

${ }^{16}$ For example, the one-day cost of paying a 1 percentage point premium on a $\$ 100$ million dollar reserve shortfall is $\$ 2,739.73$.

17 There is also no direct evidence that banks actually implement such procedures. Indeed, anecdotal evidence from reserve account managers of two very large New York banks in the late 1990s suggests that these banks did not rely on such procedures to manage their reserves.
}

requirements applies to all components of the money supply; for example,

$$
R R(M)=r r M,
$$

where $r r$ denotes a proportionate reserve requirement, say 0.10 . This assumption is crude because (i) reserve requirements do not apply equally to all components of the money supply, (ii) rr may differ for various components of alternative definitions of money, (iii) $r r$ has changed over time both exogenously and endogenously, and (iv) $r r$ is effectively zero with the introduction of lagged reserve accounting in 1998 and during the last two days of the maintenance period before the adoption of lagged reserve accounting. Despite these problems, to maintain comparability with the previous literature, equation (14) is assumed.

Second, following Hamilton (1997) we assume that money demand is a linear function of the federal funds rate; that is,

$$
f\left(f f, y_{t}\right)=\beta f f_{t}+\alpha y_{t}+\eta_{t},
$$

where $\alpha$ and $\beta$ are positive fixed parameters and $\eta_{t}$ denotes an i.i.d. random disturbance with a mean of zero and a constant variance. ${ }^{18}$ With these assumptions, equation (12) can be rewritten as

$$
f f_{t}=-(1 / r r \beta)\left[\begin{array}{l}
-r r \tilde{\beta} f f_{t}^{*}+\left(F_{t}+E_{t-1} F_{t}\right) \\
+\left(B R_{t}-I B A_{t}\right)-\left(r r \alpha y_{t}-r r \tilde{\alpha} y_{t}\right) \\
-\left(E R_{t}-E_{t-1} E R_{t}^{d}\right)+k_{t}-\eta_{t}
\end{array}\right],
$$

where $\sim$ denotes the Desk's estimate of the corresponding parameter or variable.

Thornton (2001a) has shown that estimates of the DLE can give misleading indications about the LE on days with large idiosyncratic shocks to the funds rate. In particular, the distortion can be large on settlement Wednesdays. Hence, special care is taken in estimating the DLE on days with large idiosyncratic shocks to the funds rate.

\footnotetext{
18 Equation (15) assumes that the funds rate is a reasonable proxy for the interest rate in the money demand function. However, this need not be the case. The literature on monetary demand has debated whether a long-term or short-term rate should be in the money demand function and, if it is a short-term rate, which shortterm rate it should be.
} 
Finally, Hamilton (1997) and Carpenter and Demiralp (2006) note that a necessary condition for obtaining unbiased estimates of the DLE is that reserve supply shocks be uncorrelated with shocks to money demand, $\eta_{t}$. However, equation (16) shows that the measure of reserve supply shocks that they use (i.e, a measure of $F_{t}-E_{t-1} F_{t}$ ) must also be uncorrelated with $B R_{t}-I B A_{t}, k_{t}$, $E R_{t}^{d}-E_{t-1} E R_{t}^{d}$, and $r r \alpha y_{t}-r r \tilde{\alpha} \tilde{y}_{t}$-variables not included in Hamilton's (1997) or Carpenter and Demiralp's (2006) models.

Following the literature the DLE is estimated using an EGARCH model based on equation (16). The EGARCH model is in the class of autoregressive conditional heteroskedastic (ARCH) models developed by Engle (1982) and was introduced by Nelson (1991). The specification takes the general form

$$
\mathrm{ff}_{t}=X_{t} \beta+\varepsilon_{t}, \quad t=1,2, \ldots, T,
$$

where $X_{t}$ denotes a 1-by- $l$ vector of $I$ regressors and $\beta$ denotes the corresponding $l$-by- 1 vector of coefficients. The errors, $\varepsilon_{t}$, are assumed to be conditionally heteroskedastic. Specifically,

$$
\log \sigma_{t}^{2}=\xi+\gamma\left|\frac{\varepsilon_{t-1}}{\sigma_{t-1}}\right|+\psi \frac{\varepsilon_{t-1}}{\sigma_{t-1}}+\varsigma \log \sigma_{t-1}^{2}+Z_{t} \delta+\omega_{t},
$$

where $Z_{t}$ is a 1-by- $m$ vector of observable variables that determine the evolution of the variance and $\delta$ is a corresponding $m$-by- 1 vector of coefficients. The coefficient $\psi$ allows for the possibility of asymmetry in the response of shocks to the funds rate. Because ARCH models account for heteroskedasticity, they produce estimates of $\beta$ that are generally more efficient than ordinary least squares. ${ }^{19}$

Figure 1 presents $f f_{t}$ and $f f_{t}^{*}$ over the period January 2, 1986, through January 20, 2004. It shows a number of volatility clusters typical of ARCH. Some of these are associated with welldefined events, such as the marked increases in

\footnotetext{
${ }^{19}$ However, because the EGARCH specification is not an integral part of the model, the basic equation was also estimated with ordinary least squares to determine whether the qualitative conclusions are affected by using the EGARCH model. The results indicated that the qualitative conclusions are robust to the use of the EGARCH model.
}

volatility associated with the 1987 stock market crash (bracketed by the first two vertical lines) and the surprise reduction in reserve requirements in 1990 (bracketed by the third and fourth vertical lines). There is also a marked decline in volatility that appears to begin in early 2000 (denoted by the fifth vertical line), which may be associated with changes in the FOMC's disclosure procedures. Moreover, it shows a relatively large number of volatility spikes-days when the funds rate changed by a relatively large amount only to return to essentially its previous-day's level the next day. These spikes are often unique to the funds rate. Some are associated with well-known events (e.g., settlement Wednesday and the first and last days of the year or quarter); others are not.

Hamilton (1996) found that a number of dummy variables were useful in modeling the behavior of the federal funds rate. Following Hamilton (1997) and Carpenter and Demiralp (2006), dummy variables are included for (i) each of the 10 maintenance-period days $\left(D_{i}\right.$, $i=1,2, \ldots, 10$ ); (ii) the first and last days of the month, quarter, and year (bom, eom, boq, eoq, eoy); (iii) the 15th day of the month (mom); (iv) the day before and after holidays ( $b h$ and $d h$, respectively); (v) the day before and after changes in the funds rate target (btar and atar, respectively); (vi) the month of December ( $\mathrm{dec}$ ); and (vii) the first and second week of the maintenance period $(w 1, w 2) .{ }^{20}$ Dummy variables are also included for the period of the 1987 stock market crash (d1987) and the surprise change in reserve requirements (d1990). ${ }^{21}$

The error made by the staff of the Board of Governors each day in forecasting $F_{t}$ is the reserve supply shock and is denoted miss. ${ }^{22}$ Separate

\footnotetext{
${ }^{20}$ If the 15th falls on a weekend or a holiday, mom takes on the value of 1 on the business day closest to the middle of the month.

${ }^{21} d 1987$ takes on the value of 1 from the first day of the stock market crash, October 19, 1987, through December 31, 1987, and zero elsewhere. $d 1990$ is 1.0 from the first settlement Wednesday affected by the changes, December 13, 1990, through February 28, 1991, and zero elsewhere.

22 The Board staff's estimate is a proxy because, in reality, the staffs of the Board and the New York Fed make independent estimates of the autonomous factors. The Treasury makes an independent estimate of one of the factors, namely, its balance at the Fed. Exactly how these estimates are combined each day in conducting open market operations is unclear. See Thornton (2004) for further details.
} 


\section{Figure 1}

\section{The Effective Federal Funds Rate and the FOMC's Funds Rate Target (January 2, 1986-January 20, 2004)}

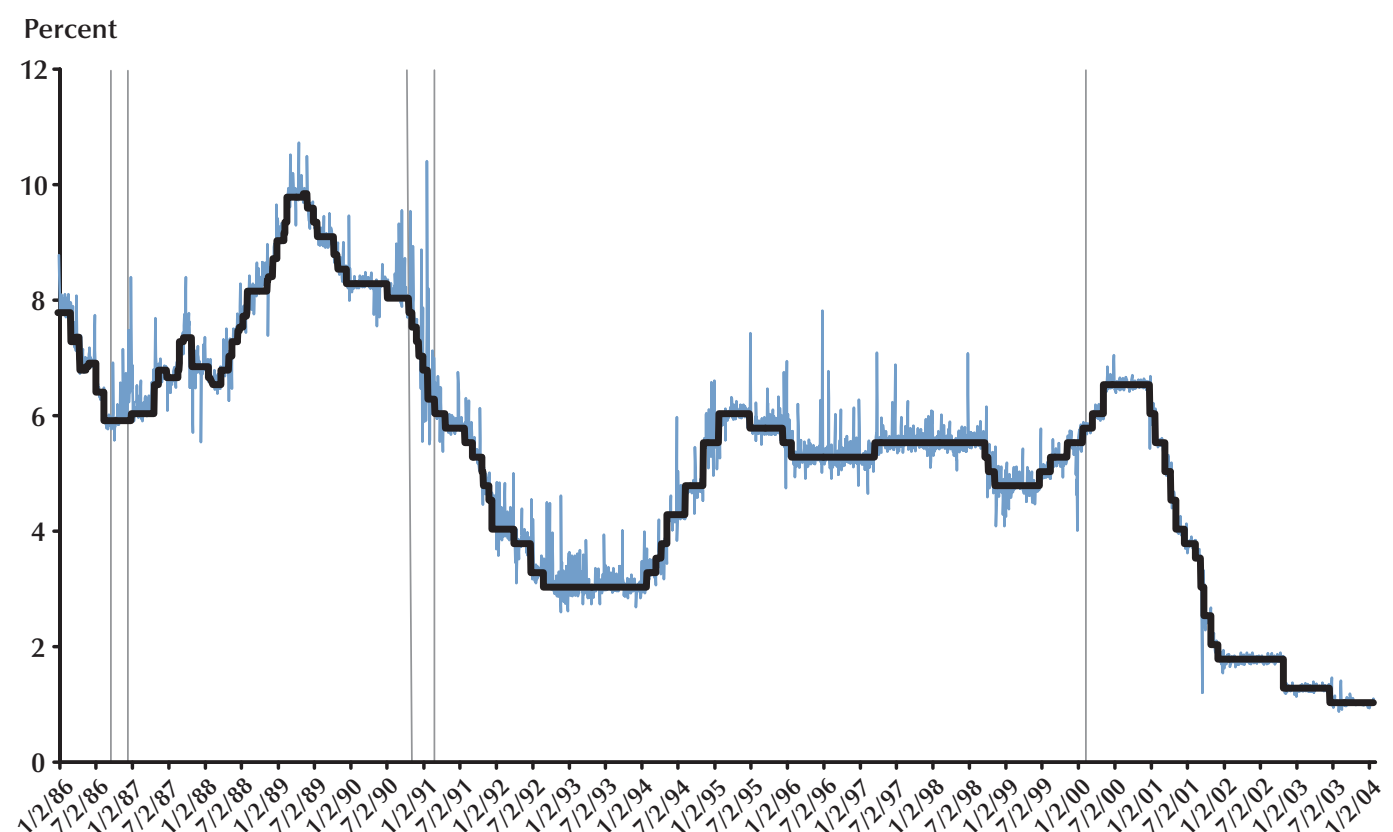

estimates of the demands for required and excess reserves are made by the staffs of the Federal Reserve Bank of New York and the Board of Governors; however, the Board's estimates are used here.

Because of the introduction of sweep accounting in January 1994, initially the model is estimated over sample period January 2, 1986, though December 31, 1993. Carpenter and Demiralp (2006) found the DLE to be nonlinear and statistically significant for large shocks (shocks $>\$ 1$ billion) but not for small shocks (shocks $\leq \$ 1$ billion). Hence, for some specifications, miss is partitioned into large shocks $\left(\operatorname{miss}_{t}^{l g}\right)$ and small shocks ( $\operatorname{miss}_{t}^{s m}$ ) using their criterion. Because of the two-day lag in the Fed's system of reserve requirements during this period, settlement days are partitioned into the last two days of the maintenance period $(12 d)$ and all other days $(n l 2 d){ }^{23}$ Also, because the effect of reserve supply shocks on the funds rate differs on days when the funds rate target is changed, dummy variables for days when the target was changed $\left(d \Delta f f_{t}^{*}\right)$ and other days $\left(d n \Delta f f_{t}^{*}\right)$ are included. Finally, the Student $t$-distribution, rather that the normal distribution, is used to account for the thick tails in the distribution of the funds rate.

The results in Table 1 are for three specifications, which differ by the variables included in the model. The coefficient estimates are presented in three sections. Table $1 \mathrm{~A}$ reports the estimates of $\beta$ for the parameters that are relevant for evaluating the DLE and the LE. Table 1B reports estimates of coefficients on the dummy variables that are included to account for various characteristics of the data. Table $1 \mathrm{C}$ reports the estimates of the variance parameters (equation 18) and the relevant summary statistics.

\footnotetext{
${ }^{23}$ Carpenter and Demiralp (2006) partition miss by each day of the maintenance period. However, save the last two days of the maintenance period, there is no particular reason to believe that the slope of the money demand curve should be systematically distinct on different days of the maintenance period. Consequently, this is not done here.
} 


\section{Table 1A}

Estimates of the Reserve Market Model (January 2, 1986-December 31, 1993)

\begin{tabular}{|c|c|c|c|c|c|c|}
\hline \multirow{2}{*}{$\frac{\text { Variable }}{f f_{t}^{*}}$} & \multicolumn{2}{|c|}{ Specification 1} & \multicolumn{2}{|c|}{ Specification 2} & \multicolumn{2}{|c|}{ Specification 3} \\
\hline & 0.5555 & 0.0000 & 0.5523 & 0.0000 & 0.5580 & 0.0000 \\
\hline$\Delta f f_{t}^{*}$ & 0.0003 & 0.3820 & 0.0004 & 0.3238 & 0.0004 & 0.3320 \\
\hline $\operatorname{miss}_{t}^{s m} \times d \Delta f f_{t}^{*}$ & 0.0104 & 0.5593 & 0.0109 & 0.1679 & 0.0106 & 0.1763 \\
\hline $\operatorname{miss}_{t}^{s m} \times d n \Delta f f_{t}^{*} \times I 2 d$ & -0.0047 & 0.8203 & & & & \\
\hline $\operatorname{miss}_{t}^{s m} \times d n \Delta f f_{t}^{*} \times n / 2 d$ & -0.0083 & 0.0219 & & & & \\
\hline $\operatorname{miss}_{t} \times d n \Delta f f_{t}^{*} \times I 2 d$ & & & -0.0327 & 0.0000 & & \\
\hline $\operatorname{miss}_{t} \times d n \Delta f f_{t}^{*} \times n / 2 d$ & & & -0.0109 & 0.0000 & & \\
\hline $\operatorname{miss}_{t} \times d n \Delta f f_{t}^{*} \times I 2 d \times O$ & & & & & -0.2181 & 0.0000 \\
\hline $\operatorname{miss}_{t} \times d n \Delta f f_{t}^{*} \times I 2 d \times N O$ & & & & & -0.0275 & 0.0001 \\
\hline $\operatorname{miss}_{t} \times d n \Delta f f_{t}^{*} \times n / 2 d \times O$ & & & & & -0.1195 & 0.0049 \\
\hline $\operatorname{miss}_{t} \times d n \Delta f f_{t}^{*} \times n / 2 d \times N O$ & & & & & -0.0108 & 0.0000 \\
\hline $\operatorname{miss}_{t}^{\lg } \times d \Delta f f_{t}^{*}$ & 0.0113 & 0.1887 & & & & \\
\hline $\operatorname{miss}_{t}^{l g} \times d n \Delta f f_{t}^{*} \times I 2 d$ & -0.0323 & 0.0000 & & & & \\
\hline$m i s s_{t}^{\lg } \times d n \Delta f f_{t}^{*} \times n / 2 d$ & -0.0114 & 0.0000 & & & & \\
\hline$B R_{t}-I B A_{t}$ & 0.0243 & 0.0000 & 0.0239 & 0.0000 & 0.0239 & 0.0000 \\
\hline$e r r_{t}^{D}$ & 0.0088 & 0.0000 & 0.0089 & 0.0000 & 0.0088 & 0.0000 \\
\hline$k_{t}$ & -0.0048 & 0.0003 & -0.0046 & 0.0005 & -0.0047 & 0.0004 \\
\hline
\end{tabular}

Consistent with the model given by equation (16), the dependent variable is $f f_{t}$ and not $f f_{t}-f f_{t}^{*}$, as in Carpenter and Demiralp (2006), or $\Delta f f_{t}$, as in Hamilton (1997). Note that $f f_{t}-f f_{t}^{*}$ would be the appropriate dependent variable if and only if the Desk correctly estimated the interest elasticity of money demand-that is, $\widetilde{\beta}=\beta .^{24}$

Specification 1 most closely resembles Carpenter and Demiralp's (2006) model. Specifically, miss $_{t}$ is partitioned into large and small misses using their criteria, and the response of the funds rate is allowed to differ depending on whether (i) the target changed that day, (ii) the miss occurred on the last two days of the mainte-

${ }^{24}$ The federal funds rate is very persistent and, hence, close to a unit root process. Hamilton's dependent variable is the change in the funds rate, while Carpenter and Demiralp's is the spread between the funds rate and the funds rate, both of which are stationary. The funds rate is used here because it is consistent with the model given by equation (16). However, to make sure that the qualitative conclusions reported here are not due solely to the near nonstationarity of the funds rate, the specifications reported in Table 1 were also estimated imposing the restriction $\widetilde{\beta}=\beta$. While the numerical values of the parameter estimates change, the important qualitative conclusions were the same. nance period, or (iii) it occurred on one of the other eight days. The estimates of the variance parameters for this specification presented in Table 1C show that the variance increased significantly during the periods immediately following the 1987 stock market crash and the 1990 surprise reduction in reserve requirements. Also, consistent with the thick-tailed distributions, characteristic of interest rates, the estimate of the degrees of freedom (dof) parameter is small, 3.77, and statistically significant, indicating the appropriateness of using the Student $t$-distribution.

All but a few of the estimates of the coefficients on the various dummy variables presented in Table 1B are statistically significant. Not surprisingly, in most cases, the estimated responses are as one would expect: The funds rate tends to be higher on settlement Wednesdays, higher at the end of the quarter, the first and last days of the month, and so on.

Table 1A reports the estimates relevant for the DLE and the LE. As expected, reserve supply shocks that occur on days when the FOMC 
Table $1 \mathrm{~B}$

Estimates of the Reserve Market Model (January 2, 1986-December 31, 1993)

\begin{tabular}{|c|c|c|c|c|c|c|}
\hline \multirow{2}{*}{$\frac{\text { Variable }}{f f_{t-1} \times w 1}$} & \multicolumn{2}{|c|}{ Specification 1} & \multicolumn{2}{|c|}{ Specification 2} & \multicolumn{2}{|c|}{ Specification 3} \\
\hline & 0.4472 & 0.0000 & 0.4504 & 0.0000 & 0.4447 & 0.0000 \\
\hline$f f_{t-1} \times w 2$ & 0.4461 & 0.0000 & 0.4494 & 0.0000 & 0.4436 & 0.0000 \\
\hline$D 1$ & -0.0132 & 0.2335 & -0.0126 & 0.2555 & -0.0130 & 0.2425 \\
\hline$D 2$ & -0.0556 & 0.0000 & -0.0691 & 0.0000 & -0.0683 & 0.0000 \\
\hline D3 & 0.0468 & 0.0000 & 0.0340 & 0.0001 & 0.0342 & 0.0001 \\
\hline D4 & -0.0287 & 0.0015 & -0.0414 & 0.0000 & -0.0413 & 0.0000 \\
\hline D5 & -0.0351 & 0.0001 & -0.0482 & 0.0000 & -0.0482 & 0.0000 \\
\hline D6 & 0.0053 & 0.6869 & -0.0085 & 0.2980 & -0.0077 & 0.3445 \\
\hline D7 & -0.0514 & 0.0001 & -0.0649 & 0.0000 & -0.0640 & 0.0000 \\
\hline$D 8$ & 0.0542 & 0.0006 & 0.0398 & 0.0006 & 0.0403 & 0.0004 \\
\hline$D 9$ & -0.0399 & 0.0224 & -0.0537 & 0.0001 & -0.0524 & 0.0002 \\
\hline$D 10$ & 0.0817 & 0.0000 & 0.0678 & 0.0000 & 0.0690 & 0.0000 \\
\hline eom & 0.0871 & 0.0000 & 0.0861 & 0.0000 & 0.0881 & 0.0000 \\
\hline bom & 0.0572 & 0.0000 & 0.0573 & 0.0000 & 0.0570 & 0.0000 \\
\hline eoq & 0.2125 & 0.0032 & 0.2159 & 0.0028 & 0.2000 & 0.0035 \\
\hline boq & -0.1152 & 0.0070 & -0.1176 & 0.0056 & -0.1202 & 0.0035 \\
\hline eoy & -0.3804 & 0.0003 & -0.3810 & 0.0003 & -0.3675 & 0.0004 \\
\hline boy & 0.4270 & 0.0006 & 0.4301 & 0.0005 & 0.4351 & 0.0005 \\
\hline mom & 0.0899 & 0.0000 & 0.0904 & 0.0000 & 0.0903 & 0.0000 \\
\hline$b h$ & -0.0169 & 0.0329 & -0.0163 & 0.0398 & -0.0173 & 0.0297 \\
\hline$a h$ & 0.1097 & 0.0000 & 0.1094 & 0.0000 & 0.1095 & 0.0000 \\
\hline
\end{tabular}

changed the funds rate target are not statistically significant, regardless of whether the shocks are large or small. Also, consistent with Carpenter and Demiralp (2006), the response of the funds rate to small shocks on all but the last two days of the maintenance period is statistically significant and smaller than the response to large shocks. However, the magnitude of the difference between the response to large and small shocks is relatively small. Indeed, the likelihood ratio test statistic for equality of the response is 0.464 , which is not statistically significant at any reasonable significance level. Contrary to Carpenter and Demiralp's (2006) results, there is no evidence of nonlinearity.

Given the absence of nonlinearity, the model is estimated without partitioning the reserve supply shocks into large and small shocks. Estimates of this specification are presented as speci- fication 2 of Table 1. Again, there is no statistically significant response of the funds rate to reserve supply shocks that occur on days when the target is changed. Also, consistent with Hamilton (1997) and Thornton (2001a), the response of the funds rate on the last two days of the maintenance period is about three times larger than the response on the other eight days, and it is statistically significant.

As expected, the coefficients on $B R_{t}-I B A_{t}$, $k_{t}$, and $\operatorname{err}_{t}^{D}$ are all statistically significant. The coefficient on $B R_{t}-I B A_{t}$ is positive, suggesting that borrowing above the FOMC's assumed level is associated with the funds rate above the target. The sign of the coefficient is inconsistent with a supply shock interpretation, but it is consistent with the evidence that borrowing responds endogenously to the funds rate (e.g., Thornton, 2001b). The coefficients on $k_{t}$ and $\operatorname{err}_{t}^{D}$ have the 


\section{Table 1C}

Estimates of the Reserve Market Model (January 2, 1986-December 31, 1993)

\begin{tabular}{|c|c|c|c|c|c|c|}
\hline \multirow{2}{*}{$\frac{\text { Variable }}{\text { Constant }}$} & \multicolumn{2}{|c|}{ Specification 1} & \multicolumn{2}{|c|}{ Specification 2} & \multicolumn{2}{|c|}{ Specification 3} \\
\hline & -3.0817 & 0.0000 & -3.0848 & 0.0000 & -3.0208 & 0.0000 \\
\hline$\left|\varepsilon_{t-1} / \sigma_{t-1}\right|$ & 0.7053 & 0.0000 & 0.7043 & 0.0000 & 0.6821 & 0.0000 \\
\hline$\varepsilon_{t-1} / \sigma_{t-1}$ & 0.0559 & 0.2237 & 0.0585 & 0.2058 & 0.0638 & 0.1507 \\
\hline $\log \sigma_{t-1}^{2}$ & 0.5387 & 0.0000 & 0.5374 & 0.0000 & 0.5466 & 0.0000 \\
\hline$D 1+D 2+D 3$ & 1.5364 & 0.0000 & 1.5356 & 0.0000 & 1.5135 & 0.0000 \\
\hline btar & 0.6902 & 0.0085 & 0.6768 & 0.0086 & 0.6660 & 0.0097 \\
\hline$a h$ & 1.1983 & 0.0000 & 1.2091 & 0.0000 & 1.1562 & 0.0000 \\
\hline eom & 0.9886 & 0.0000 & -1.8576 & 0.0096 & -1.6951 & 0.0161 \\
\hline eoq & 2.4000 & 0.0000 & 2.4184 & 0.0000 & 2.3238 & 0.0000 \\
\hline eoy & -1.8168 & 0.0108 & 0.9883 & 0.0000 & 0.9508 & 0.0000 \\
\hline mom & 0.6470 & 0.0028 & 0.6558 & 0.0024 & 0.6322 & 0.0033 \\
\hline$d 1987$ & 0.4993 & 0.0239 & 0.4942 & 0.0251 & 1.3252 & 0.0000 \\
\hline$d 1990$ & 1.3196 & 0.0000 & 1.3238 & 0.0000 & 0.5740 & 0.0099 \\
\hline Degrees of freedom & 3.7653 & 0.0000 & 3.7529 & 0.0000 & 3.7440 & 0.0000 \\
\hline No. of observations & 1,966 & & 1,966 & & 1,966 & \\
\hline $\bar{R}^{2}$ & 0.9887 & & 0.9885 & & 0.9892 & \\
\hline SE & 0.2234 & & 0.2244 & & 0.2180 & \\
\hline Log likelihood & 1477.061 & & 1475.596 & & 1479.130 & \\
\hline
\end{tabular}

anticipated signs. The estimated coefficient on $k_{t}$ suggests that the funds rate tends to be significantly lower on days when the Desk engages in more open market operations than the operating procedure suggests. Likewise, if the Desk underestimates the demand for reserves, the funds rate is somewhat higher.

Equation (16) suggests that the absolute magnitude of the response of the funds rate to miss, $e r r_{t}^{D}, B R_{t}-I B A_{t}$, and $k_{t}$ should be equal; however, this restriction was not imposed. ${ }^{25}$ Nevertheless, it is interesting to note that the estimated coefficients on $\operatorname{err}_{t}^{D}$ and miss on days other than the last two of the maintenance period are similar in magnitude but opposite in sign as suggested by

${ }^{25}$ Given that borrowing is endogenous, it is unlikely that the restriction would hold for borrowing. Also given that the Desk is free to deviate from the procedure as it sees fit, it seems unlikely that it would hold for $k_{t}$ as well. Indeed, a test that the absolute values of the coefficients on miss, $\operatorname{err}_{t}^{D}$, and $k_{t}$ are equal is rejected at the 5 percent significance level or lower. equation (16). The likelihood ratio statistic for the hypothesis that the responses are equal but opposite in sign is 0.79 .

Thornton (2001a) showed that Hamilton's (1997) results were sensitive to days with large shocks to the funds rate. Hence, I investigate the sensitivity of the estimates of the DLE to unusually large and idiosyncratic shocks to the funds rate. This is important because the response of the funds rate to supply shocks on such days is not necessarily evidence of an LE. Specifically, miss is partitioned by days with large and idiosyncratic shocks to the funds rate: outliers $(O)$ and days with no outliers $(N O)$. Days with idiosyncratic shocks to the funds rate are obtained by regressing the federal funds rate on a constant and the 3month Treasury bill rate over the sample period. The residuals from this equation are daily changes in the funds rate that are not associated with changes in the 3-month T-bill rate: idiosyncratic shocks to the federal funds rate. Idiosyncratic 


\section{Table 2}

\section{Estimates of the Reserve Market Model (January 3, 1994-December 31, 1996)}

\begin{tabular}{|c|c|c|}
\hline Variable & Coefficient & $\begin{array}{c}\text { Significance } \\
\text { level }\end{array}$ \\
\hline$f f_{t}^{*}$ & 0.769 & 0.000 \\
\hline$\Delta f f_{t}^{*}$ & -0.000 & 0.820 \\
\hline$m i s s_{t}^{s m} \times d \Delta f f_{t}^{*}$ & 0.769 & 0.000 \\
\hline $\operatorname{miss}_{t} \times d n \Delta f f_{t}^{*} \times I 2 d \times O$ & 0.000 & 0.820 \\
\hline $\operatorname{miss}_{t} \times d n \Delta f f_{t}^{*} \times I 2 d \times N O$ & -0.008 & 0.881 \\
\hline $\operatorname{miss}_{t} \times d n \Delta f f_{t}^{*} \times n / 2 d \times O$ & -0.011 & 0.281 \\
\hline $\operatorname{miss}_{t} \times d n \Delta f f_{t}^{*} \times n / 2 d \times N O$ & -0.004 & 0.051 \\
\hline$B R_{t}-I B A_{t}$ & 0.198 & 0.000 \\
\hline$e r r_{t}^{D}$ & 0.004 & 0.006 \\
\hline$k_{t}$ & 0.000 & 0.770 \\
\hline No. of observations & 754 & \\
\hline $\bar{R}^{2}$ & 0.946 & \\
\hline SE & 0.197 & \\
\hline Log likelihood & 789.248 & \\
\hline
\end{tabular}

shocks to the funds are considered large when they are more than 80 basis points (roughly two standard errors [SEs] of the idiosyncratic shocks to the funds rate). ${ }^{26}$ There are 62 days when there were large, idiosyncratic shocks to the funds rate during the sample period (slightly more than 3 percent of the days), 33 of which occurred on a settlement Tuesday or Wednesday.

The results are reported in specification 3 of Table 1. As anticipated, estimates of the DLE are sensitive to large idiosyncratic shocks to the funds rate. On days with large idiosyncratic shocks to the funds rate, the estimated DLE is about 10 times larger than on days without such shocks. Consistent with the results of Thornton (2001a), estimates of the DLE appear to be significantly overestimated on days with large idiosyncratic shocks to the funds rate. Nevertheless, the estimate on days other than the last two of the maintenance period reported in specification 2 is nearly

\footnotetext{
${ }^{26}$ As a robustness check on the qualitative results, values of 40, 50, and 60 basis points were also used. The qualitative conclusion about the coefficient miss on NO days is invariant to the value used.
}

identical to the estimate when there are no outliers in specification 3 . Hence, the effect of large, idiosyncratic shocks to the funds rate is reflected mostly in estimates on settlement Tuesday and Wednesday. ${ }^{27}$

\section{Post-1993 Estimates of the Daily Liquidity Effect}

The introduction of sweep accounts in January 1994 dramatically reduced reserve requirements for banks over time. Anderson and Rasche (2001) suggest that by the end of 1999, "the willingness of bank regulators to permit use of deposit-sweeping software has made statutory reserve requirements a 'voluntary constraint' for most banks" (p. 71). To investigate the effect of sweep accounts on the estimate of the DLE, the model is estimated over the period from January 3, 1994, through December 31, 1996. To conserve space, only estimates of the parameters that are relevant for the LE are reported in Table 2. All estimated coefficients on the various partitions of miss are much smaller in absolute value than those reported in Table 1. Moreover, none is statistically significant at the 5 percent significance level. The estimate is statistically significant at slightly higher than the 5 percent significance level when miss is partitioned by $n l 2 d$ and NO. The estimate is only about half as large as that for the pre-1994 period. The smaller estimate is inconsistent with the fact that sweeps effectively reduce reserve requirements. Other things the same, lower effective reserve requirements should have resulted in a larger coefficient estimate. One possible explanation is that the effective elimination of mandatory reserve requirements for nonbound banks significantly altered the interest sensitivity of reserve demand independent of money demand. It is interesting to note that the estimated coefficient on miss for these days is again equal but opposite in sign to that of reserve demand shocks.

\footnotetext{
${ }^{27}$ Given the close relationship between the funds rate and the funds rate target, the model was also estimated using $f f_{t}-f f_{t}^{*}$ as the dependent variable. While the coefficient estimates changed somewhat, the qualitative conclusions are not sensitive to whether $f f_{t}$ or $f f_{t}-f f_{t}^{*}$ is the dependent variable. The quantitative and qualitative results are very sensitive to excluding $B R_{t}-I B A_{t}$, $e r r_{t}^{D}$, and $k_{t}$, however. The correlations between miss and $B R_{t}-I B A_{t}$, $\operatorname{err}_{t}^{D}$, and $k_{t}$ over this sample period are $-0.058,0.352$, and -0.013 , respectively.
} 


\section{Post-1998 Estimates of the Daily Liquidity Effect}

Finally, the model was estimated over the period August 3, 1998, through January 30, 2004, to determine whether such evidence has no implication for the LE. Data on $B R_{t}-I B A_{t}$, $e r r_{t}^{D}$, and $k_{t}$ are not available over this period, so the estimates are likely to be biased. The estimate of the DLE for days other than the last two of the maintenance period when there were no outliers is small, -0.007 , but statistically significant. This shows that the demand for reserves is interest sensitive apart from the interest sensitivity of the demand for money. Given the interest sensitivity of reserve demand, caution is necessary in concluding that there is a statistically significant and economically relevant LE based on statistically significant estimates of the DLE.

\section{CONCLUSION}

The DLE was first estimated by Hamilton (1997) in an attempt to find evidence of Friedman's (1969) policy-relevant LE, which had escaped detection using lower-frequency (monthly and quarterly) data. Unfortunately, Hamilton and subsequent researchers did not investigate the linkage between the DLE and the LE. This article fills this gap in the literature by showing that the DLE is directly linked to the LE by Federal Reserveimposed reserve requirements. The relationship between the DLE and the LE is then analyzed and investigated using a more comprehensive model of the Desk's operating procedure than has been used in the literature. The analysis shows that the relationship between the DLE and the LE depends on the Desk's operating procedure, the
Fed's system of reserve requirements, and other factors. Importantly, the analysis shows that there is no relationship between these LEs after July 1998 when the Fed reinstated lagged reserve accounting.

Estimates of the DLE before 1994 suggest that there may have been a statistically significant policy-relevant LE before 1994. The estimated DLE is small, however. The estimate suggests that a $\$ 10$ billion reserve supply shock generates about a 20-basis-point change in the funds rate. If one assumes that the average effective reserve requirement during the sample period is 10 percent, this would be equivalent to about a $\$ 100$ billion shock to the money supply-much larger than any shock during this sample period.

More problematic is the finding of a statistically significant DLE after July 1998, when the Fed established lagged reserve accounting. The existence of a DLE over this period is due to the fact that banks have an incentive to economize on their holdings of reserves, independent of the interest sensitivity of money demand. The fact that there is a statistically significant DLE during a period when estimates of the DLE can have no implication for the LE raises a question of the extent to which estimates of the DLE have implications for the LE during other periods. It could be that all estimates of the DLE reflect the interest sensitivity of reserve demand independent of the interest sensitivity of money demand. In any event, the results presented here indicate that it is no easier to find convincing evidence of a statistically significant and economically important policy-relevant LE using high-frequency daily data than it has been using lower-frequency (monthly and quarterly) data. A resolution of the liquidity puzzle remains elusive.

\section{REFERENCES}

Anderson, Richard G. and Rasche, Robert H. "Retail Sweep Programs and Bank Reserves, 1994-1999.” Federal Reserve Bank of St. Louis Review, January/February 2001, 83(1), pp. 51-72; http://research.stlouisfed.org/publications/review/01/0101ra.pdf.

Bartolini, Leonardo; Bertola, Giuseppe and Prati, Alessando. "Day-to-Day Monetary Policy and the Volatility of the Federal Funds Interest Rate.” Journal of Money, Credit, and Banking, February 2002, 34(1), pp. 137-59. 


\section{Thornton}

Cagan, Phillip and Gandolfi, Arthur. "The Lag in Monetary Policy as Implied by the Time Pattern of Monetary Effects on Interest Rates.” American Economic Review, May 1969, 59(2), pp. 277-84.

Carpenter, Seth and Demiralp, Selva. "The Liquidity Effect in the Federal Funds Market: Evidence from Daily Open Market Operations." Journal of Money, Credit, and Banking, June 2006, 38(4), pp. 901-20.

Clouse, James A. and Dow, James P. Jr. "A Computational Model of Banks' Optimal Reserve Management Policy." Journal of Economic Dynamics and Control, September 2002, 26(11), pp. 1787-814.

Coleman, Wilbur John II; Gilles, Christian and Labadie, Pamela A. "A Model of the Federal Funds Market." Economic Theory, February 1996, 7(2), pp. 337-57.

Engle, Robert F. "Autoregressive Conditional Heteroscedasticity with Estimates of the Variance of United Kingdom Inflation.” Econometrica, July 1982, 50(4), pp. 987-1007.

Feinman, Joshua N. "Estimating the Open Market Desk's Daily Reaction Function.” Journal of Money, Credit, and Banking, May 1993, 25(2), 231-47.

Friedman, M. "Factors Affecting the Level of Interest Rates," in Proceedings of the 1968 Conference on Saving and Residential Financing. Chicago: United States Saving and Loan League, 1969, pp. 11-27. Reprinted in Thomas M. Havrilesky and John T. Boorman, eds., Current Issues in Monetary Theory and Policy. Arlington Heights, IL: AHM Publishing, 1976, pp. 362-78.

Gibson, William E. "Interest Rates and Monetary Policy.” Journal of Political Economy, May/June 1970a, 78(3), pp. 431-55.

Gibson, William E. “The Lag in the Effect of Monetary Policy on Income and Interest Rates.” Quarterly Journal of Economics, May 1970b, 84(2), pp. 288-300.

Hamilton, James D. "The Daily Market for Federal Funds.” Journal of Political Economy, February 1996, 104(1), pp. 26-56.

Hamilton, James D. "Measuring the Liquidity Effect.” American Economic Review, March 1997, 87(1), pp. 80-97.

Humphrey, Thomas M. “The Early History of the Real/Nominal Interest Rate Relationship.” Federal Reserve Bank of Richmond Economic Review, May/June 1983a, 69(3), pp. 2-10; www.richmondfed.org/publications/research/economic review/1983/pdf/er690301.pdf.

Humphrey, Thomas M. "Can the Central Bank Peg Real Interest Rates? A Survey of Classical and Neoclassical Opinion.” Federal Reserve Bank of Richmond Economic Review, September/October 1983b, 69(5), pp. 12-21; http://www.richmondfed.org/publications/research/economic review/1983/pdf/er690502.pdf.

Judson, Ruth and Klee, Elizabeth. "Whither the Liquidity Effect: The Impact of Federal Reserve Open Market Operations in Recent Years." Finance and Economics Discussion Series Working Paper 2009-25, Board of Governors of the Federal Reserve System; www.federalreserve.gov/pubs/feds/2009/200925/200925pap.pdf.

Nelson, Daniel B. “Conditional Heteroskedasticity in Asset Returns: A New Approach.” Econometrica, March 1991, 59(2), pp. 347-70.

Pagan, Adrian R. and Robertson, John C. "Resolving the Liquidity Effect.” Federal Reserve Bank of St. Louis Review, May/June 1995, 77(3), pp. 33-54;

http://research.stlouisfed.org/publications/review/95/05/Resolving May_June1995.pdf.

Strongin, Steven. "The Identification of Monetary Policy Disturbances: Explaining the Liquidity Puzzle.” Journal of Monetary Economics, June 1995, 35(3), pp. 463-97.

Thornton, Daniel L. “The Borrowed-Reserves Operating Procedure: Theory and Evidence.” Federal Reserve Bank of St. Louis Review, January/February 1988, 70(1), pp. 30-54; http://research.stlouisfed.org/publications/review/88/01/Borrowed Jan Feb1988.pdf. 
Thornton, Daniel L. "Identifying the Liquidity Effect at the Daily Frequency." Federal Reserve Bank of St. Louis Review, July/August 2001a, 83(4), pp. 59-78;

http://research.stlouisfed.org/publications/review/01/05/59-78Thornton.qxd.pdf.

Thornton, Daniel L. "The Federal Reserve's Operating Procedure, Nonborrowed Reserves, Borrowed Reserves and the Liquidity Effect." Journal of Banking and Finance, September 2001b, 25(9), pp. 1717-39.

Thornton, Daniel L. "Forecasting the Treasury's Balance at the Fed.” Journal of Forecasting, August 2004, 23(5), pp. 357-71.

Thornton, Daniel L. "When Did the FOMC Begin Targeting the Federal Funds Rate? What the Verbatim Transcripts Tell Us.” Journal of Money, Credit, and Banking, December 2006, 38(8), pp. 2039-71.

Thornton, Daniel L. "Open Market Operations and the Federal Funds Rate," in David G. Mayes and Jan Toporowski, eds., Open Market Operations and the Financial Markets. Oxford, UK: Routledge, 2007; pp. 178-205.

Reprinted in the Federal Reserve Bank of St. Louis Review, November/December 2007, 89(6), pp. 549-72; http://research.stlouisfed.org/publications/review/07/11/Thornton.pdf. 
